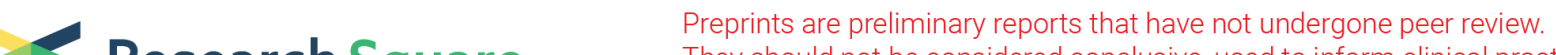 $\begin{array}{ll}\text { Research Square } & \text { They should not be considered conclusive, used to inform clinical practice, } \\ \text { or referenced by the media as validated information. }\end{array}$
}

\section{The (1-x)BiFe03-xBaTiO3-Bi(Zn0.5Ti0.5)03 high temperature lead-free piezoelectric ceramics with strong piezoelectric properties}

\section{Yuanyuan Sun}

Guilin University of Electronic Technology

Huabin Yang ( $\sim$ 495221054@qq.com )

Guilin University of Electronic Technology https://orcid.org/0000-0001-8382-3552

Jiwen Xu

Guilin University of Electronic Technology

Weiran Huang

Guilin University of Electronic Technology

Minhong Jiang

Guilin University of Electronic Technology

Qiaohong Chen

Guilin University of Electronic Technology

\section{Research Article}

Keywords: BiFe03-BaTiO3, Piezoelectric, Lead-free piezoelectric ceramics, Phase structure, High Curie temperature

Posted Date: March 24th, 2021

DOI: https://doi.org/10.21203/rs.3.rs-329232/v1

License: (c) (i) This work is licensed under a Creative Commons Attribution 4.0 International License. Read Full License

Version of Record: A version of this preprint was published at Journal of Materials Science: Materials in Electronics on July 11th, 2021. See the published version at https://doi.org/10.1007/s10854-021-06494-1. 


\section{Abstract}

The structure, microstructure, piezoelectric properties, ferroelectric properties and Curie temperature of (1x ) $\mathrm{BiFeO} 3-\mathrm{x}$ BaTiO $3-\mathrm{Bi}(\mathrm{Zn} 0.5 \mathrm{Ti} 0.5) \mathrm{O} 3+\mathrm{MnO} 2+\mathrm{Li} 2 \mathrm{CO} 3$ ceramics were investigated experimentally by improved solid-state reaction approach. The crystalline structures were examined by X-ray diffractometry. When $x=0.3$, the rhombohedral and pseudocubic phases coexist in the ceramic structure. It is considered that the morphotropic phase boundary was formed here. At the same time, the piezoelectric performance $d 33$, Curie temperature $T C$, and depolarization temperature are as high as $184 \mathrm{pC} / \mathrm{N}, 550^{\circ} \mathrm{C}, 530^{\circ} \mathrm{C}$ at $\mathrm{x}=0.3$, respectively. It is worth noting that when $\mathrm{x}=0.24$, the ceramics have a high $\mathrm{T} \mathrm{C}=580^{\circ} \mathrm{C}$ and low dielectric loss $\tan \delta=1.9 \%$. These results show that the BFBT-BZT system ceramics are applicable ceramics with high piezoelectric properties in high temperature fields.

\section{Introduction}

Piezoelectric ceramics are commonly used in sensors, transducers and many other fields [1,2,3]. High temperature piezoelectric materials may be applied in nuclear energy, oil well drilling, aerospace vehicles, geological mining $[4,5]$. PZT ceramics are a kind of piezoelectric ceramic material which are widely produced in industry. However, PZT piezoelectric ceramics pollute the environment and damage the body in the production process $\$ and its piezoelectric performance is limited in high temperature fields $[6,7]$. Therefore, lead-free piezoelectric ceramics have become a hot spot in current research. The Curie temperature of $\mathrm{K}_{0.5} \mathrm{Na}_{0.5} \mathrm{NbO}_{3}$ and $\mathrm{Bi}_{0.5} \mathrm{Na}_{0.5} \mathrm{TiO}_{3}$ based ceramics are far from satisfying the application of high temperature fields [8-10]. Lead-free piezoelectric ceramics with bismuth layered are usually utilized in higher temperature fields, but the piezoelectric properties are lower [11,12].

$\mathrm{BiFeO}_{3}$ is a twisted trigonal perovskite structure with high Curie temperature. The $\mathrm{BiFeO}_{3}-\mathrm{BaTiO}_{3}(\mathrm{BFBT})$ binary system shows high $T_{\mathrm{C}}$ in the components of the rhombohedral and pseudocubic phase boundaries [13]. Related studies have reported the influence of $\mathrm{Mn}$ doped on BFBT ceramics, and obtained the piezoelectric ceramics with $d_{33}=169 \mathrm{pC} / \mathrm{N}, T_{\mathrm{C}}=506^{\circ} \mathrm{C}, T_{\mathrm{d}}=500^{\circ} \mathrm{C}$, $\tan \delta \approx 4.4 \%[14] . \mathrm{Bi}\left(\mathrm{Zn}_{0.5} \mathrm{Ti}_{0.5}\right) \mathrm{O}_{3}$ (BZT) is a Bi-based perovskite compound, the large residual polarization and high tetragonality are $P_{\mathrm{r}}>$ $150 \mu \mathrm{C} / \mathrm{cm}^{2}, \mathrm{c} / \mathrm{a}=1.21$, respectively [15]. BFBT-BZT $+\mathrm{MnO}_{2}$ ternary solid solution reduces the dielectric loss and improves the temperature stability of ceramics [16-18]. $\mathrm{Li}_{2} \mathrm{CO}_{3}$ is a conventional sintering aid, when $\mathrm{Li}_{2} \mathrm{CO}_{3}$ was added into ceramics, which promotes ceramic sintering and makes $\mathrm{BFBT}-\mathrm{BZT}+\mathrm{MnO}_{2}$ ceramics dense [19-22].

However, in the sintering process, $\mathrm{Bi}_{2} \mathrm{O}_{3}$ is volatile and the change of $\mathrm{Fe}^{3+}$ into $\mathrm{Fe}^{2+}$ in $\mathrm{BiFeO}_{3}$ caused a number of oxygen vacancies in ceramics [23]. This phenomenon makes less compact sintering of ceramics. Therefore, the stoichiometric ratio of $\mathrm{BF} / \mathrm{BT}$ in ceramics became the focus of the experiment. So, the experiment made the ceramics dense by changing the contents of $\mathrm{BF}$ and $\mathrm{BT}$, and it was believed that the piezoelectric properties can still be improved, and the low dielectric loss can be obtained of the ceramics. In this paper, $(1-x) \mathrm{BiFeO}_{3}-x \mathrm{BaTiO}_{3}-0.025 \mathrm{Bi}\left(\mathrm{Zn}_{0.5} \mathrm{Ti}_{0.5}\right) \mathrm{O}_{3}+0.0035 \mathrm{MnO}_{2}+0.003 \mathrm{Li}_{2} \mathrm{CO}_{3}$ (where $x=$ 
$0.24,0.26,0.28,0.30,0.32,0.34 \mathrm{~mol} \%$, abbreviated as (1-x)BF-xBT-BZT) lead-free piezoelectric ceramics were prepared by solid phase sintering. The phase transition, microstructure, electrical properties, Curie temperature and depolarization temperature of the ceramics were investigated experimentally. After a series of studies, the ceramics obtained with high piezoelectric properties and high Curie temperature in morphotropic phase boundary (MPB). Related studies are listed in Table 1 and Table 2.

\section{Experimental}

The (1-x) BF- $x$ BT-BZT ceramics were made by solid-state reaction method using $\mathrm{Bi}_{2} \mathrm{O}_{3}, \mathrm{Fe}_{2} \mathrm{O}_{3}, \mathrm{BaCO}_{3}, \mathrm{TiO}_{2}$, $\mathrm{ZnO}, \mathrm{MnO}_{2}$, and $\mathrm{Li}_{2} \mathrm{CO}_{3}$ as raw materials, the purity of all raw materials is more than $99 \%$. The dried raw material powders were prepared in proportion and then ball milled for $24 \mathrm{~h}$ by alcohol. After that, the raw materials were dried, sieved and then calcined at $780{ }^{\circ} \mathrm{C}$ for $4 \mathrm{~h}$. The powders synthesized after sintering was ball milled again then dried. The powders were mixed with $8 \mathrm{wt} \% \mathrm{PVA}$ and dried, raw plain disks with a diameter of $12 \mathrm{~mm}$ were made under $10 \mathrm{MPa}$. Finally, all samples were sintered at $960-1000^{\circ} \mathrm{C}$ for $2-8$ h. After the above steps, the crystal structure and phase transformation of the ceramics were analyzed by X-ray diffraction analysis, referred to as XRD (D8-2-Advanced, Bruker AXS, Germany). This experiment used scanning electron microscopy (SEM, JSM-5610LV, JEOL, Japan) to observe the microstructure of ceramic samples. And the experiment measured the piezoelectric constant by $d_{33}$ quasi-static instrument (ZJ-3A, CAS, Shanghai, China). For the planar electromechanical coupling factor $k_{\mathrm{p}}$ and mechanical quality factors $Q_{m}$ were determined through precision impedance analyzer (4294A, Agilent Company). The polarization hysteresis loop was tested by a ferroelectric tester (Premier II, Radiation Technology Corporation, Albuquerque, NM, USA). Dielectric temperature spectrum of samples at room temperature to $700^{\circ} \mathrm{C}$ was measured by dynamic impedance analyzer (Agilent 4294A). The non - in - situ method measured the depolarization temperature of samples in this experiment.

\section{Results And Discussion}

Fig. 1 shows the XRD patterns of (1-x)BF-XBT-BZT ceramics samples. The main structure of all samples is $\mathrm{ABO}_{3}$-type perovskite structure. This phenomenon shows that the ceramics have formed a homogeneous ternary solid solution $[35,36]$. In order to descript the phase structure transition of the ceramics more carefully, the characteristic peak near $39^{\circ}$ are enlarged as displayed in Fig. 1(b). When the content of $\mathrm{BaTiO}_{3}$ increases from 0.24 to 0.34 , the characteristic peak evolved from the double peak (003 and 021) to a single peak (111). The shift is mainly near $x=0.3$. When the range of $x$ is $0.24-0.28$, the phase structure of ceramics is rhombohedral. When $x \geq 0.32$, the phase structure converted to pseudocubic phase. The rhombohedral and the pseudocube phase coexist when $x$ is around 0.3 , the existence of MPB in 0.7BF-0.3BT-BZT sample $[25,27,37]$.

Fig. 2-1 is the surface microstructures of $(1-x)$ BF-xBT-BZT ceramics sintered at $980^{\circ} \mathrm{C}$. Fig. $2-2$ is the average grain size distributions of the ceramics. All samples have no obvious holes, which could be reflected in the SEM micrographs of different BT contents. When $x=0.24$, the average grain size of 
ceramics is relatively larger. With the content of BT increases, the grain size of the ceramics decreases significantly. When $x \geq 0.28$, the grain sizes don't become smaller anymore and tend to be stable. The reason for this phenomenon is that $\mathrm{BF}$ is a low-melting material [38]. At the same sintering temperature, more BF promotes grain growth and reduces sintering temperature. Furthermore, with the increase of BT, the oxygen vacancies decrease during $\mathrm{BF}$ sintering process (the change of $\mathrm{Fe}^{3+}$ to $\mathrm{Fe}^{2+}$ and the volatility of $\left.\mathrm{Bi}_{2} \mathrm{O}_{3}\right)[23,32,39]$, which is not conducive to grain transfer, and ultimately inhibits grain growth [40]. It is worth noted that the liquid phase appears clearly at $x=0.3$, which indicates that the BF and BT content reaches the optimal ratio and promoted sintering.

Fig. 3 presents the variation trend of piezoelectric constant $d_{33}$, electromechanical coupling coefficient $k_{\mathrm{p}}$, mechanical mass factor $Q_{\mathrm{m}}$ and dielectric loss $\tan \delta$ with BT content. The $d_{33}$ and $k_{\mathrm{p}}$ increase first and reach the maximum $d_{33}=184 \mathrm{pC} / \mathrm{N}, k_{\mathrm{p}}=0.335$ at $x=0.3$, then decrease with the change of BT. The $\tan \delta$ increases and the $Q_{\mathrm{m}}$ shows a downward trend with the rise of $x, \tan \delta=1.9 \%$ and $Q_{\mathrm{m}}=72.71$ respectively at $x=0.24$. According to the XRD results, the phase structure in the MPB range is formed near $x=0.3$ of the sample. For the ceramic with the MPB structure, the drive energy required for the domain wall movement of the ceramics is lowered, and the domain activity is increased so the piezoelectric property can be improved remarkably $[25,41,42]$. The main reason for the decrease of $Q_{m}$ and the increase of $\tan \delta$ is that with the BT content increases, the oxygen vacancies decrease due to the change of $\mathrm{Fe}^{3+}$ to $\mathrm{Fe}^{2+}$. Furthermore, the reduction of oxygen vacancies makes it easier to turn the domain, which makes $\tan \delta$ increase, $Q_{\mathrm{m}}$ decrease and increases the aging rate of ceramics.

At room temperature, the $P$-E hysteresis loop are depicted as Fig. 4, and $P, E, P_{\mathrm{r}}, E_{\mathrm{c}}$ represent polarization intensity, applied electric field, residual polarization intensity and coercive field, respectively. The used electric field in ferroelectric behavior test is from $30 \mathrm{kV} / \mathrm{cm}$ to $60 \mathrm{kV} / \mathrm{cm}$. From the Fig. 4, typical ferroelectric polarization hysteresis loops were shown. Except for $x=0.24$, the remaining ceramics samples are in a relatively saturated state when $E$ is $60 \mathrm{kV} / \mathrm{cm}$. As we can see from Fig. $4(\mathrm{~g})$ when $x$ rises from 0.24 to $0.26, P_{\mathrm{r}}$ and $E_{\mathrm{c}}$ increase significantly. $P_{\mathrm{r}}$ slowly increases to a maximum $20.13 \mu \mathrm{C} / \mathrm{cm}^{2}$ at $x=$ 0.34 , the $E_{\mathrm{c}}$ reaches $33.77 \mathrm{kV} / \mathrm{cm}$ which is the maximum value at $x=0.26$ and then it shows a decreasing trend. The reason why $P_{\mathrm{r}}$ increases is that favorable uniformity of grain size and the improving densification of structure with the increase of BT content, which means the more completed polarization and stronger ferroelectric properties. The sudden increase for $E_{\mathrm{c}}$ is caused by the decrease in grain size when $x=0.24$ to 0.26 . The increase of grain boundaries makes it difficult to flip the domain $[16,17,18]$, the $P_{\mathrm{r}}$ becomes larger slightly, but $E_{\mathrm{c}}$ becomes smaller as the grain continues to decrease. It is noted in Fig. $4(\mathrm{e}-\mathrm{f})$ that the hysteresis loop is not smooth under the $E$ of $60 \mathrm{kV} / \mathrm{cm}$, this is because the high electric field caused the ceramic sample to leak current $[14,16]$.

Fig. 5(a-f) shows the $e_{\mathrm{r}}$ and $\tan \delta$ of all samples, $e_{\mathrm{r}}$ represents dielectric constant and $\tan \delta$ represents loss tangent. The frequencies are $1 \mathrm{kHz}, 10 \mathrm{kHz}$ and $100 \mathrm{kHz}$, respectively. All ceramic samples have good temperature dependence from room temperature to $700^{\circ} \mathrm{C}$. The $e_{\mathrm{r}}$ varies little when the temperature 
increase at the beginning, it rapidly increases to the peak at a certain temperature $\left(T_{\mathrm{c}}\right)$, and finally decreases. As shown in Fig. $5(\mathrm{~g}), T_{\mathrm{C}}$ reaches the maximum of $580^{\circ} \mathrm{C}$ when $x=0.24$, and Curie temperature reduces with the increase of BT. The $\tan \delta$ increases before reaching the $T_{\mathrm{C}}$ when the rang of $x$ is 0.24 to 0.28 . And the $\tan \delta$ decreases at the Curie point, increases again with the temperature increases. When $x \geq 0.30$, the $\tan \delta$ increases rapidly after Curie point decreases.

According to the modified Curie-Weiss law:

$$
1 / \varepsilon_{\mathrm{r}}-1 / \varepsilon_{\mathrm{m}}=\left(T-T_{\mathrm{m}}\right)^{\gamma} / C \quad(1 \leq \gamma \leq 2)
$$

where the curve of $\ln \left(1 / e_{\mathrm{r}}-1 / e_{\mathrm{m}}\right)$ as a function of $\ln \left(T-T_{\mathrm{m}}\right)$ for the ceramics, which are presented in Fig. $5(\mathrm{~h})$. In the formula, $e_{\mathrm{m}}$ is the maximum value of $e_{\mathrm{r}}, T_{\mathrm{m}}$ denotes phase transition temperature, $C$ is Curielike constant and $y$ is degree of diffuseness. Furthermore, the range of $y$ is from 1 to 2 , where 1 represents a normal ferroelectric, 2 represents ideal relaxor ferroelectric [29]. It can be seen from Fig. 5(a-f), all (1$x)$ BF- $x$ BT-BZT ceramics are relaxor ferroelectrics. Under the $T_{\mathrm{C}}$, with the increase of frequency $(1 \mathrm{kHz}$ to $100 \mathrm{kHz})$, the $e_{\mathrm{r}}$ decreases, the $\tan \delta$ generates $(x<0.30)$, the dielectric peak and the loss peak move toward the high temperature, all of which are caused by the frequency dispersion characteristics of relaxation ferroelectrics [16]. Above the $T_{\mathrm{c}}$, the $\tan \delta$ of the samples increase again because the ceramics have a slight leakage current at high temperature. With the increase of $x$, the Curie temperature reduces, which is due to the increase of dielectric loss at room temperature which caused by oxygen vacancy in the sintering process. It is worth noting that when $x<0.3$, with the frequency increases, the $e_{\mathrm{r}}$ decreases before the Curie point. And when $x \geq 0.3$, the loss peak disappears, which is due to the reason that the frequency dispersion of the relaxed ferroelectric weakened. The trend of $e_{r}$ and $\tan \delta$ for all $(1-x) \mathrm{BF}-x \mathrm{BT}-$ BZT samples is consistent with $y$ of relaxation ferroelectrics.

The depolarization curve of the (1-x)BF-xBT-BZT ceramics is depicted in the Fig. 6 . The $d_{33}$ of the samples as a function of temperature was measured by ex - situ $d_{33}$ method. With the increase of temperature, there is no obvious change for $d_{33}$. When a certain temperature $\left(T_{\mathrm{d}}\right)$ arrives, the $d_{33}$ drops suddenly $[26,43]$. For ceramic samples with $x=0.24$, when the depolarization temperature is $550^{\circ} \mathrm{C}, d_{33}=85 \mathrm{pC} / \mathrm{N}$. When $x=0.3$ and $T_{\mathrm{d}}=530^{\circ} \mathrm{C}$, the $d_{33}$ is still as high as $150 \mathrm{pC} / \mathrm{N}$. The figure shows that depolarization law of all ceramic samples is consistent with the variation of the Curie temperature as Fig. $5(\mathrm{~g})$. When the BT content ranges from 0.24 to 0.34 , the decrease of depolarization temperature is due to the increasing loss for the ceramics, as described in Fig. 3(b). When $x=0.3$, the high $d_{33}$ is caused by the ceramic at MPB.

\section{Conclusions}

The (1-x)BF-xBT-BZT ceramics were synthesized by solid-state sintering method. The effect of BT as a variable on the structure, micromorphology, piezoelectric, ferroelectric properties and Curie temperature of ceramics was investigated. The XRD analysis results indicate that the rise of BT can cause a phase 
transformation from rhombohedral to pseudocubic phase. The (1-x)BF- $x$ BT-BZT system has a MPB at $x=$ 0.3. And the $0.7 \mathrm{BF}-0.3 \mathrm{BT}-\mathrm{BZT}$ ceramics exhibit the best $d_{33}=184 \mathrm{pC} / \mathrm{N}$, and high $T_{\mathrm{C}}=550^{\circ} \mathrm{C}$, particularly when $T_{\mathrm{d}}=530^{\circ} \mathrm{C}, d_{33}=150 \mathrm{pC} / \mathrm{N}$. It is worth pointing out that the $0.76 \mathrm{BF}-0.24 \mathrm{BT}-\mathrm{BZT}$ ceramic has excellent Curie temperature $T_{\mathrm{C}}=580^{\circ} \mathrm{C}$, and low dielectric loss $\tan \delta=1.9 \%$. The high electrical properties and improved temperature stability demonstrates that the ceramics we prepared can be used effectively in high temperature field.

\section{Declarations}

\section{Acknowledgements}

This work was supported by the National Nature Science Foundation of China (11664006 and 11364008), Natural Science Foundation of Guangxi (2014GXNSFAA118311), and Guangxi Key Laboratory of Information Materials.

\section{References}

1. H. Khansura, J. Glaumb, O. Clemens, et al, Uniaxial compressive stress and temperature dependent mechanical behavior of $(1-x) \mathrm{BiFeO}_{3}-x \mathrm{BaTiO}_{3}$ lead-free piezoelectric ceramics, Ceram. Int. 43, 90929098 (2017)

2. Gao, R. Hong, J. Liu, et al, Phase formation and characterization of high Curie temperature $x \mathrm{BiYbO}_{3}-$ (1-x) $\mathrm{PbTiO}_{3}$ piezoelectric ceramics, J. Eur. Ceram. Soc. 29, 1687-1693 (2009)

3. Y Chen, J Zhu, D Xiao, et al, Bismuth-modified $\mathrm{BiScO}_{3}-\mathrm{PbTiO}_{3}$, piezoelectric ceramics with high Curie temperature, Mater. Lett. 62, 3567-3569 (2008)

4. Cen, C. Zhou, H. Yang, et al, Structural, ferroelectric and piezoelectric properties of Mn-modified $\mathrm{BiFeO}_{3}-\mathrm{BaTiO}_{3}$ high-temperature ceramics, J. Mater. Sci: Mater. Electron. 24, 3952-3957 (2013)

5. J. Lee, S.J. Zhang, Y. Bar-Cohen, et al, High temperature, high power piezoelectric composite transducers, Sensors. 14, 14526-14552 (2014)

6. Rodel, K.G. Webber, R. Dittmer, et al, Transferring lead-free piezoelectric ceramics into application, J. Eur. Ceram. Soc. 35, 1659-1681 (2015)

7. A. Malik, A. Hussain, A. Maqbool, et al, Giant strain, thermally-stable high energy storage properties and structural evolution of Bi-based lead-free piezoceramics, J. Alloys Compd. 682, 302-310 (2016)

8. A. Rafiq, M.E. Costa, P.M. Vilarinho, Pairing high piezoelectric coefficient $d_{33}$, with high Curie temperature $\left(T_{C}\right)$ in lead-free $(\mathrm{K}, \mathrm{Na}) \mathrm{NbO}_{3}$, ACS Appl. Mater. Inter. 8, 33755-33764 (2016)

9. Zhang, R. Xia, T.R. Shrout, Piezoelectric properties in perovskite $0.948\left(\mathrm{~K}_{0.5} \mathrm{Na}_{0.5}\right) \mathrm{NbO}_{3}-0.052 \mathrm{LiSbO}_{3}$ lead-free ceramics, J. Appl. Phys. 100, 104108 (2006)

10. Ren, J. He, X. Wang, High-temperature dielectrics based on (1- $x)\left[0.94 \mathrm{Bi}_{0.5} \mathrm{Na}_{0.5} \mathrm{TiO}_{3}-0.06 \mathrm{BaTiO}_{3}-\right.$ $\left.0.03 \mathrm{AgNbO}_{3}\right]-\mathrm{XK}_{0.5} \mathrm{Na}_{0.5} \mathrm{NbO}_{3}$, J. Mater. Sci: Mater. Electron. 29, 17016-17021 (2018) 
11. Nie, Q. Chen, $\mathrm{H}$. Liu, et al, $\mathrm{MnO}_{2}$-doped $\left(\mathrm{Ca}_{0.4} \mathrm{Sr}_{0.6}\right) \mathrm{Bi}_{4} \mathrm{Ti}_{4} \mathrm{O}_{15}$ high-temperature piezoelectric ceramics with improved thermal stability, J. Mater. Sci. 51, 5104-5112 (2016)

12. Zhou, Y. Li, S. Hui, et al, Effect of tungsten doping in bismuth-layered $\mathrm{Na}_{0.5} \mathrm{Bi}_{2.5} \mathrm{Nb}_{2} \mathrm{O}_{9}$ high temperature piezoceramics, Appl. Phys. Lett. 104, 012904 (2014)

13. Kim, G.P. Khanal, H.W. Nam, Structural and electrical characteristics of potential candidate lead-free $\mathrm{BiFeO}_{3}-\mathrm{BaTiO}_{3}$ piezoelectric ceramic, J. Appl. Phys. 122, 164105 (2017)

14. Li, J. Wei, J. Cheng, et al, High temperature dielectric, ferroelectric and piezoelectric properties of Mnmodified $\mathrm{BiFeO}_{3}-\mathrm{BaTiO}_{3}$ lead-free ceramics, J. Mater. Sci. 52, 229-237 (2017)

15. R. Suchomel, A.M. Fogg, A. Mathieu, et al, $\mathrm{Bi}\left(\mathrm{Zn}_{1 / 2} \mathrm{Ti}_{1 / 2}\right) \mathrm{O}_{3}$ : A Lead-free closed-shell polar perovskite with a calculated ionic polarization of $150 \mu \mathrm{C} / \mathrm{cm}^{2}$, Chem. Mater. 18, 4987-4989 (2006)

16. H. Ryu, A. Hussain, M.H. Lee, et al, Lead-free high performance $\mathrm{Bi}\left(\mathrm{Zn}_{0.5} \mathrm{Ti}_{0.5}\right) \mathrm{O}_{3}$-modified $\mathrm{BiFeO}_{3^{-}}$ $\mathrm{BaTiO}_{3}$ piezoceramics, J. Eur. Ceram. Soc. 38, 4414-4421 (2018)

17. Shan, C. Zhou, Z. Cen, et al, Structural phase boundary of $\mathrm{BiFeO}_{3}-\mathrm{Bi}\left(\mathrm{Zn}_{1 / 2} \mathrm{Ti}_{1 / 2}\right) \mathrm{O}_{3}-\mathrm{BaTiO}_{3}$ lead-free ceramics and their piezoelectric properties, Ceram. Int. 39, 6707-6712 (2013)

18. Guan, H. Yang, G. Chen, et al, Microstructure, piezoelectric, and ferroelectric properties of BZTmodified $\mathrm{BiFeO}_{3}-\mathrm{BaTiO}_{3}$ multiferroic ceramics with $\mathrm{MnO}_{2}$ and $\mathrm{CuO}$ addition, J. Electron. Mater. 47, 2625-2633 (2018)

19. W. Lou, J.T. Zeng, Z.Y. Man, et al, Sintering behavior of high-concentration $\mathrm{Li}_{2} \mathrm{CO}_{3}$-doped $\mathrm{BaTiO}_{3}$ ceramics, Appl. Phys. A 125, 263 (2019)

20. Kimura, Q. Dong, S. Yin, et al, Synthesis and piezoelectric properties of $\mathrm{Li}$-doped $\mathrm{BaTiO}_{3}$ by a solvothermal approach, J. Eur. Ceram. Soc. 33, 1009-1015 (2013)

21. Guan, H. Yang, Y. Zhao, et al, Effect of $\mathrm{Li}_{2} \mathrm{CO}_{3}$ addition in $\mathrm{BiFeO}_{3}-\mathrm{BaTiO}_{3}$ ceramics on the sintering, J. Alloys Compd. 735, 386-393 (2018)

22. Sun, $\mathrm{H}$. Yang, S. Guan et al, Strong piezoelectricity of $\mathrm{Li}_{2} \mathrm{CO}_{3}$-doped $\mathrm{BiFeO}_{3}-\mathrm{BaTiO}_{3}-\mathrm{Bi}\left(\mathrm{Zn}_{0.5} \mathrm{Ti}_{0.5}\right) \mathrm{O}_{3}$ lead-free piezoelectric ceramics with high Curie temperature and high temperature stability, J. Alloys Compd. 819, 153058 (2020)

23. S. Kim, C.I. Cheon, S.S. Lee, et al, Effect of cooling rate on phase transitions and ferroelectric properties in $0.75 \mathrm{BiFeO}_{3}-0.25 \mathrm{BaTiO}_{3}$ ceramics, Appl. Phys. Lett. 109, 202902 (2016)

24. Liaoa, X. Chena, X. Chu, et al, Effect of Fe doping on the structure and electric properties of relaxor type BSPT-PZN piezoelectric ceramics near the morphotropic phase boundary. Sensor. Actuat. A. 201, 222-229 (2013)

25. Yang, C. Zhou, X. Liu, et al, Structural, microstructural and electrical properties of $\mathrm{BiFeO}_{3}-\mathrm{BaTiO}_{3}$ ceramics with high thermal stability, Mater. Res. Bull. 47, 4233-4239 (2012)

26. Yang, C. Zhou, X. Liu, et al, Piezoelectric properties and temperature stabilities of Mn and Cu-modified $\mathrm{BiFeO}_{3}-\mathrm{BaTiO}_{3}$ high temperature ceramic, J. Eur. Ceram. Soc. 33, 1177-1183 (2013) 
27. Cen, C. Zhou, J. Cheng, et al, Effect of $\mathrm{Zr}^{4+}$ substitution on thermal stability and electrical properties of high temperature $\mathrm{BiFe}_{0.99} \mathrm{Al}_{0.01} \mathrm{O}_{3}-\mathrm{BaTi}_{1-x} \mathrm{Zr}_{x} \mathrm{O}_{3}$ ceramics, J. Alloys Compd. 567, 110-114 (2013)

28. Zhou, C. Zhou, Q. Zhou, et al, Investigation of structural and electrical properties of B-site complex Ion $\left(\mathrm{Mg}_{1 / 3} \mathrm{Nb}_{2 / 3}\right)^{4+}$-modified high-Curie-temperature $\mathrm{BiFeO}_{3}-\mathrm{BaTiO}_{3}$ ceramics, J. Electron. Mater. 43, 755760 (2014)

29. Guo, T. Wang, D. Shi, et al, Strong piezoelectricity and multiferroicity in $\mathrm{BiFeO}_{3}-\mathrm{BaTiO}_{3}-\mathrm{NdCoO}_{3}$ leadfree piezoelectric ceramics with high Curie temperature for current sensing application, J. Mater. Sci: Mater. Electron. 28, 5531-5547 (2017)

30. Zheng, Y. Guo, F. Lei, et al, Microstructure, ferroelectric, piezoelectric and ferromagnetic properties of $\mathrm{BiFeO}_{3}-\mathrm{BaTiO}_{3}-\mathrm{Bi}\left(\mathrm{Zn}_{0.5} \mathrm{Ti}_{0.5}\right) \mathrm{O}_{3}$ lead-free multiferroic ceramics, J. Mater. Sci: Mater. Electron. 25, 2638-2648 (2014)

31. H. Lee, D.J. Kim, J.S. Park, et al, High-performance Lead-free piezoceramics with high Curie temperatures, Adv. Mater. 27, 6976-6982 (2015)

32. Lin, L. Zhang, W. Zheng, et al, Structural phase boundary of $\mathrm{BiFeO}_{3}-\mathrm{Bi}\left(\mathrm{Zn}_{1 / 2} \mathrm{Ti}_{1 / 2}\right) \mathrm{O}_{3}-\mathrm{BaTiO}_{3}$ lead-free ceramics and their piezoelectric properties, J. Mater. Sci: Mater. Electron, 26, 7351-7360 (2015)

33. Liu, T. Zheng, C. Zhao, et al, Composition design and electrical properties in $\mathrm{BiFeO}_{3}-\mathrm{BaTiO}_{3}$ $\mathrm{Bi}\left(\mathrm{Zn}_{0.5} \mathrm{Ti}_{0.5}\right) \mathrm{O}_{3}$ lead-free ceramics, J. Mater. Sci: Mater. Electron. 28, 13076-13083 (2017)

34. Chen, B. Zhang, L. Zhu, et al, Enhanced insulation resistance and electrical properties of $\mathrm{BiFe}_{1}$ ${ }_{x}\left(\mathrm{Zn}_{0.5} \mathrm{Ti}_{0.5}\right)_{x} \mathrm{O}_{3}-\mathrm{BaTiO}_{3}$ lead-free piezoceramics, Ceram. Int. 44, 8409-8416 (2018)

35. Wan, Y. Li, Q. Li, et al, Microstructure, ferroelectric, piezoelectric, and ferromagnetic properties of Scmodified $\mathrm{BiFeO}_{3}-\mathrm{BaTiO}_{3}$ multiferroic ceramics with $\mathrm{MnO}_{2}$ addition, J. Am. Ceram. Soc. 97, 1809-1818 (2014)

36. Zhao, Y. Hou, X. Yu, et al, Construction of high $T_{\mathrm{C}} \mathrm{BiScO}_{3}-\mathrm{BiFeO}_{3}-\mathrm{PbTiO}_{3}$ and its enhanced piezoelectric properties by sintering in oxygen atmosphere, J. Appl. Phys. 124, 194103 (2018)

37. F. Zhu, B.P. Zhang, S. Li, et al, Enhanced piezoelectric properties of $\mathrm{Bi}\left(\mathrm{Mg}_{1 / 2} \mathrm{Ti}_{1 / 2}\right) \mathrm{O}_{3}$ modified $\mathrm{BiFeO}_{3^{-}}$ $\mathrm{BaTiO}_{3}$ ceramics near the morphotropic phase boundary, J. Alloys Compd. 664, 602-608 (2016)

38. Mahesh Kumar, V.R. Palkar, K. Srinivas, et al, Ferroelectricity in pure $\mathrm{BiFeO}_{3}$ ceramic, Appl. Phys. Lett. 76,2764 (2000)

39. Lin, J. Yu, Ferroelectric and piezoelectric properties of high temperature perovskite-type $0.69 \mathrm{BiFeO}_{3}-$ $0.02 \mathrm{Bi}\left(\mathrm{Mg}_{1 / 2} \mathrm{Ti}_{1 / 2}\right) \mathrm{O}_{3}-0.29 \mathrm{BaTiO}{ }_{3}$ ceramics, J. Mater. Sci. Mater. Electron. 25, 5462-5466(2014)

40. O. Leontsev, R.E. Eitel, Dielectric and piezoelectric propertiesin Mn-modified (1-x) $\mathrm{BiFeO}_{3}-x \mathrm{BaTiO}_{3}$ ceramics, J. Am. Ceram. Soc. 92, 2957-2961 (2009)

41. D. Hou, L.M. Chang, M.K. Zhu, et al, Effect of $\mathrm{Li}_{2} \mathrm{CO}_{3}$ addition on the dielectric and piezoelectric responsesin the low-temperature sintered 0.5PZN-0.5PZT systems, J. Appl. Phys. 102, 4507 (2007)

42. Mitsuia, I. Fujiia, K. Nakashimaa, et al, Enhancement in the piezoelectric properties of $\mathrm{BaTiO}_{3}{ }^{-}$ $\mathrm{Bi}\left(\mathrm{Mg}_{1 / 2} \mathrm{Ti}_{1 / 2}\right) \mathrm{O}_{3}-\mathrm{BiFeO}_{3}$ system ceramics by nanodomain, Ceram. Int. 39, 695-699 (2013) 
43. Zhou, C. Zhou, H. Yang, et al, Dielectric, ferroelectric, and piezoelectric properties of $\mathrm{Bi}\left(\mathrm{Ni}_{1 / 2} \mathrm{Ti}_{1 / 2}\right) \mathrm{O}_{3^{-}}$ modified $\mathrm{BiFeO}_{3}-\mathrm{BaTiO}_{3}$ ceramics with high Curie temperature, J. Am. Ceram. Soc. 95, 3889-3893 (2012)

\section{Tables}

Table 1. $d_{33}, T_{\mathrm{C}}$, and $T_{\mathrm{d}}$ of the reported piezoelectric ceramics.

\begin{tabular}{|c|c|c|c|}
\hline Systems & $\begin{array}{l}d_{33} \\
(\mathrm{pC} / \mathrm{N})\end{array}$ & $\begin{array}{l}T_{c} \\
\left({ }^{\circ} \mathrm{C}\right)\end{array}$ & $\begin{array}{l}T_{d} \\
\left({ }^{\circ} \mathrm{C}\right)\end{array}$ \\
\hline $0.35 \mathrm{BiScO}_{3}-0.6 \mathrm{PbTiO}_{3}-0.05\left(\mathrm{Zn}_{1 / 3} \mathrm{Nb}_{2 / 3}\right) \mathrm{O}_{3}[24]$ & 470 & 420 & 260 \\
\hline $0.725 \mathrm{BiFeO}_{3}-0.275 \mathrm{BaTiO}_{3}[25]$ & 136 & 485 & 420 \\
\hline $0.71 \mathrm{BiFeO}_{3}-0.29 \mathrm{BaTiO}_{3}+1.0 \mathrm{~mol}_{0} \mathrm{MnO}_{2}[14]$ & 140 & 512 & 500 \\
\hline$(1-x) \mathrm{BiFeO}_{3}-x \mathrm{BaTiO}_{3}+0.4 \mathrm{wt} \% \mathrm{CuO}+0.6 \mathrm{wt} \% \mathrm{MnO}_{2}[26]$ & 170 & 485 & 480 \\
\hline $0.725 \mathrm{BiFeO}_{3}-0.275 \mathrm{BaTiO}_{3}+0.35 \mathrm{~mol}^{2} \mathrm{MnO}_{2}+0.3 \mathrm{~mol}^{2} \mathrm{Li}_{2} \mathrm{CO}_{3}[21]$ & 163 & 508 & 480 \\
\hline $0.72 \mathrm{BiFe}_{0.99} \mathrm{Al}_{0.01} \mathrm{O}_{3}-0.28 \mathrm{BaTi}_{0.97} \mathrm{Zr}_{0.03} \mathrm{O}_{3}[27]$ & 157 & 435 & 425 \\
\hline $0.71 \mathrm{BiFeO}_{3}-0.29 \mathrm{BaTi}\left(\mathrm{Mg}_{1 / 3} \mathrm{Nb}_{2 / 3}\right) \mathrm{O}_{3}[28]$ & 158 & 453 & 400 \\
\hline $0.71 \mathrm{BiFe}_{0.9}\left(\mathrm{Zn}_{1 / 2} \mathrm{Ti}_{1 / 2}\right)_{0.1} \mathrm{O}_{3}-0.29 \mathrm{BaTiO}_{3}[16]$ & 163 & 428 & 380 \\
\hline $0.75 \mathrm{BiFeO}_{3}-0.25 \mathrm{BaTiO}_{3}-0.01 \mathrm{NdCoO}_{3}+1 \mathrm{~mol}^{2} \mathrm{MnO}_{2}[29]$ & 110 & 605 & 525 \\
\hline $\begin{array}{l}0.7 \mathrm{BiFeO}_{3}-0.3 \mathrm{BaTiO}_{3}-0.025 \mathrm{Bi}\left(\mathrm{Zn}_{0.5} \mathrm{Ti}_{0.5}\right)+0.003 \mathrm{MnO}_{2}+0.003 \mathrm{Li}_{2} \mathrm{CO}_{3}[22]^{\text {Our }} \\
\text { work }\end{array}$ & 184 & 554 & 530 \\
\hline $\begin{array}{l}0.76 \mathrm{BiFeO}_{3}-0.24 \mathrm{BaTiO}_{3}-0.025 \mathrm{Bi}\left(\mathrm{Zn}_{0.5} \mathrm{Ti}_{0.5}\right) \mathrm{O}_{3}+0.0035 \mathrm{MnO}_{2}+0.003 \mathrm{Li}_{2} \mathrm{CO}_{3}{ }^{\text {This }} \\
\text { work }\end{array}$ & 102 & 580 & 550 \\
\hline
\end{tabular}

Table 2. $d_{33}, T_{\mathrm{C}}$, and $T_{\mathrm{d}}$ of the reported BF-BT-BZT piezoelectric ceramics. 


\begin{tabular}{|c|c|c|c|}
\hline BF-BT-BZT System & $\begin{array}{l}d_{33} \\
(\mathrm{pC} / \mathrm{N})\end{array}$ & $\begin{array}{l}T_{\mathrm{c}} \\
\left({ }^{\circ} \mathrm{C}\right)\end{array}$ & $\begin{array}{l}T_{d} \\
\left({ }^{\circ} \mathrm{C}\right)\end{array}$ \\
\hline $0.71 \mathrm{BiFe}_{0.9}\left(\mathrm{Zn}_{1 / 2} \mathrm{Ti}_{1 / 2}\right)_{0.1} \mathrm{O}_{3}-0.29 \mathrm{BaTiO}_{3}+0.6 \mathrm{wt} \% \mathrm{MnO}_{2}[17]$ & 163 & 428 & 380 \\
\hline $0.65 \mathrm{BiFeO}_{3}-0.30 \mathrm{BaTiO}_{3}-0.05 \mathrm{Bi}\left(\mathrm{Zn}_{0.5} \mathrm{Ti}_{0.5}\right) \mathrm{O}_{3}+1 \mathrm{~mol}_{0} \mathrm{MnO}_{2}[30]$ & 139 & 565 & - \\
\hline $0.97\left[0.67 \mathrm{Bi}_{1.05} \mathrm{FeO}_{3}-0.33 \mathrm{BaTiO}_{3}\right]-0.03 \mathrm{Bi}_{1.05}\left(\mathrm{Zn}_{0.5} \mathrm{Ti}_{0.5}\right) \mathrm{O}_{3}[31]$ & 324 & 466 & - \\
\hline $0.696 \mathrm{BiFeO}_{3}-0.014 \mathrm{Bi}\left(\mathrm{Zn}_{0.5} \mathrm{Ti}_{0.5}\right) \mathrm{O}_{3}-0.28 \mathrm{BaTiO}_{3}+0.26 \mathrm{wt} \% \mathrm{MnO}_{2}[32]$ & 147 & 514 & - \\
\hline $0.99\left[0.715 \mathrm{BiFeO}_{3}-0.285 \mathrm{BaTiO}_{3}\right]-0.01 \mathrm{Bi}\left(\mathrm{Zn}_{0.5} \mathrm{Ti}_{0.5}\right) \mathrm{O}_{3}[33]$ & 195 & 505 & 400 \\
\hline $0.67 \mathrm{BiFeO}_{3}-0.33 \mathrm{BaTiO}_{3}-0.03 \mathrm{Bi}\left(\mathrm{Zn}_{0.5} \mathrm{Ti}_{0.5}\right) \mathrm{O}_{3}+0.0035 \mathrm{MnO}_{2}+0.004 \mathrm{CuO}$ [18] & 188 & 420 & 426 \\
\hline 0.7BiFe ${ }_{0.95}-0.05\left(\mathrm{Zn}_{0.5} \mathrm{Ti}_{0.5}\right)_{0.03} \mathrm{O}_{3}-0.3 \mathrm{BaTiO}_{3}[34]$ & 135 & 482 & - \\
\hline $0.98\left[0.60 \mathrm{BiFeO}_{3}-0.40 \mathrm{BaTiO}_{3}\right]-0.02 \mathrm{Bi}_{1.05}\left(\mathrm{Zn}_{0.5} \mathrm{Ti}_{0.5}\right) \mathrm{O}_{3}[16]$ & 50 & 350 & - \\
\hline $\begin{array}{l}0.7 \mathrm{BiFeO}_{3}-0.3 \mathrm{BaTiO}_{3}-0.025 \mathrm{Bi}\left(\mathrm{Zn}_{0.5} \mathrm{Ti}_{0.5}\right)+0.0035 \mathrm{MnO}_{2}+0.003 \mathrm{Li}_{2} \mathrm{CO}_{3}[22]^{\mathrm{Our}} \\
\text { work }\end{array}$ & 184 & 554 & 530 \\
\hline $\begin{array}{l}0.76 \mathrm{BiFeO}_{3}-0.24 \mathrm{BaTiO}_{3}-0.025 \mathrm{Bi}\left(\mathrm{Zn}_{0.5} \mathrm{Ti}_{0.5}\right) \mathrm{O}_{3}+0.0035 \mathrm{MnO}_{2}+0.003 \mathrm{Li}_{2} \mathrm{CO}_{3}{ }^{\text {This }} \\
\text { work }\end{array}$ & 102 & 580 & 550 \\
\hline
\end{tabular}

\section{Figures}

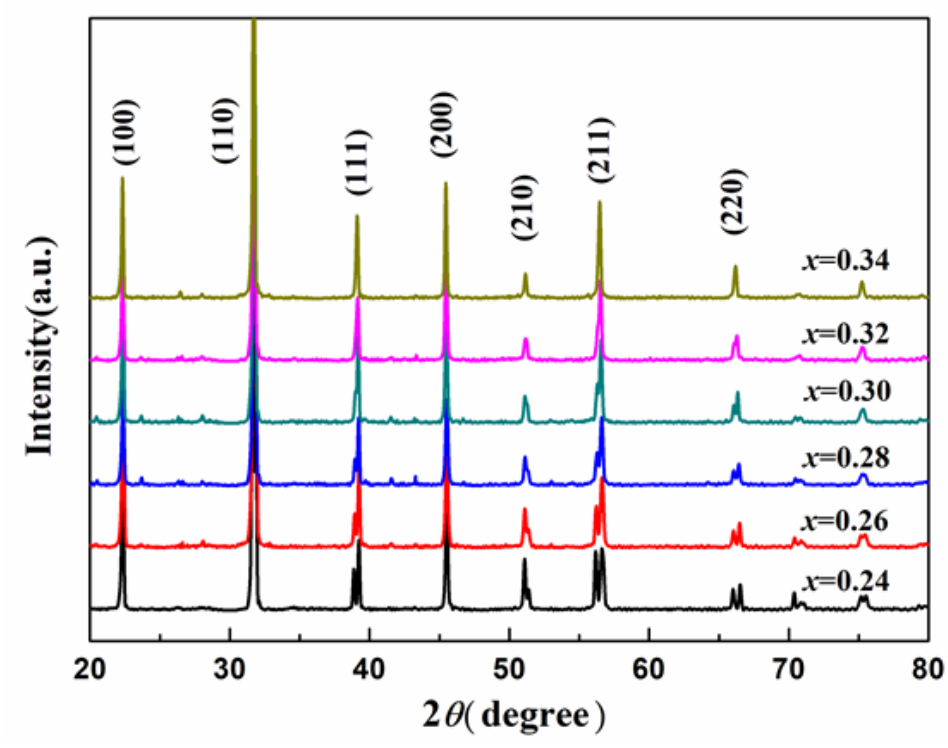

(a)

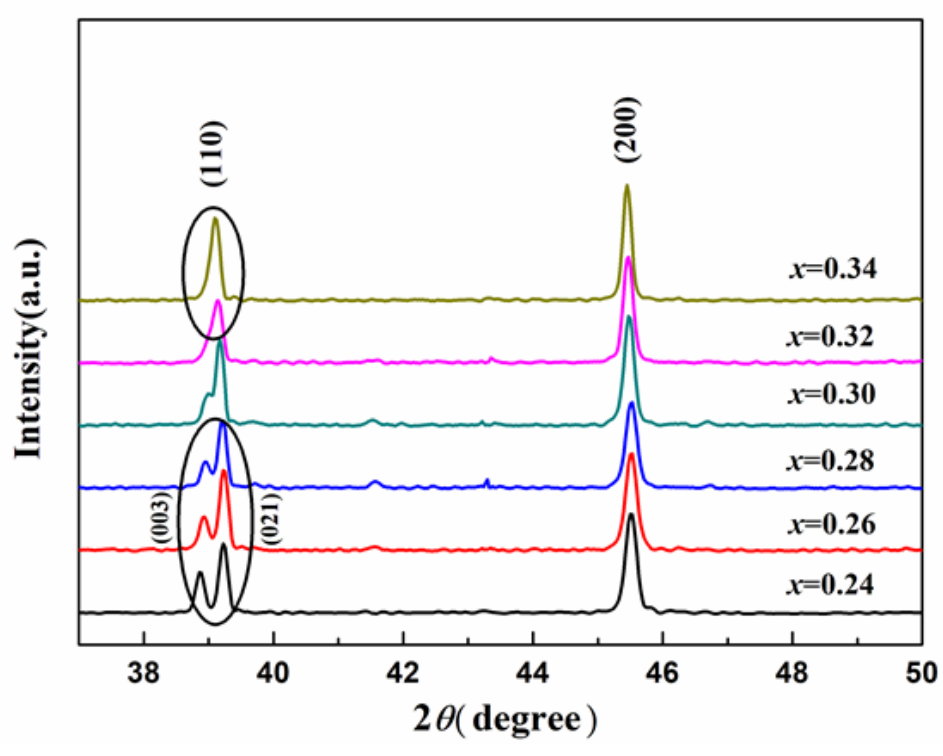

(b)

Figure 1 
(a)Room temperature X-ray diffraction patterns of (1-x)BF-xBT-BZT ceramics. (b) The enlargement of XRD in $2 \theta$ range of $38^{\circ}-50^{\circ}$.
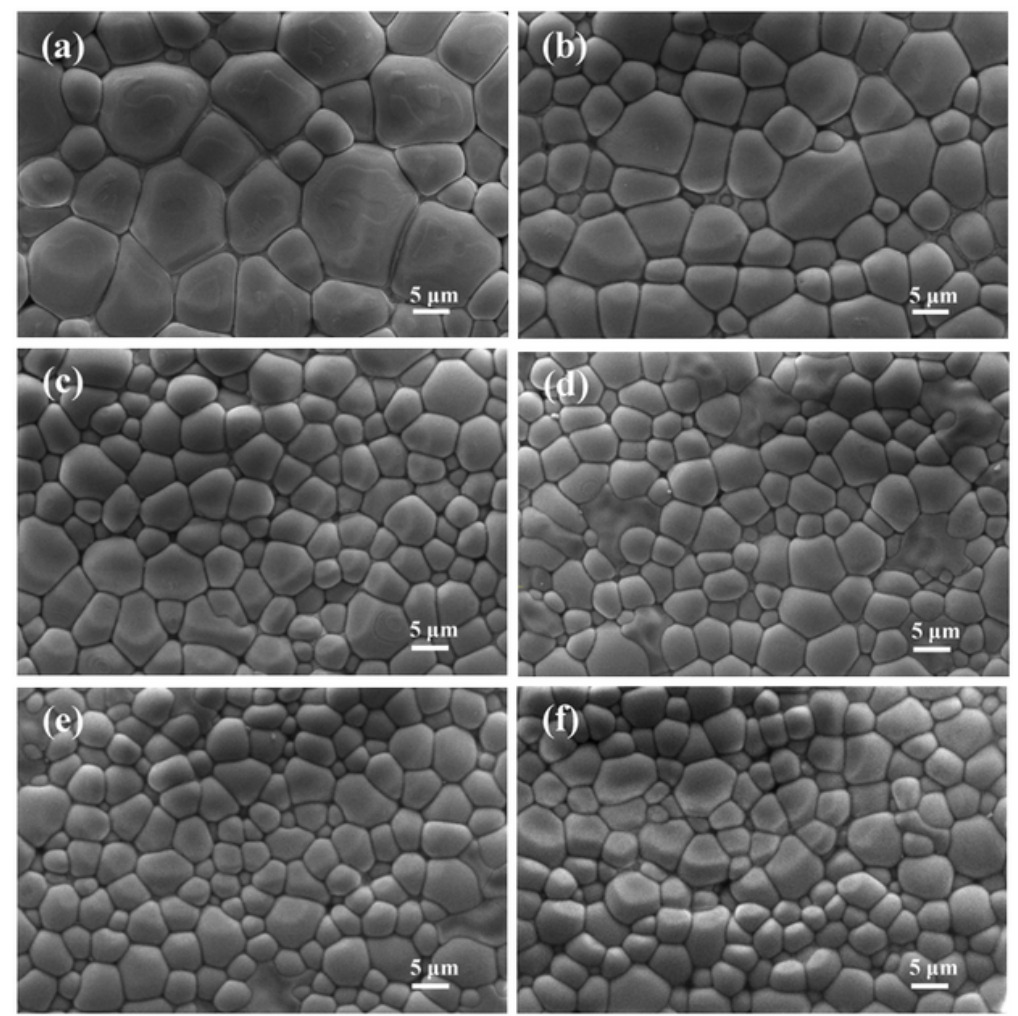

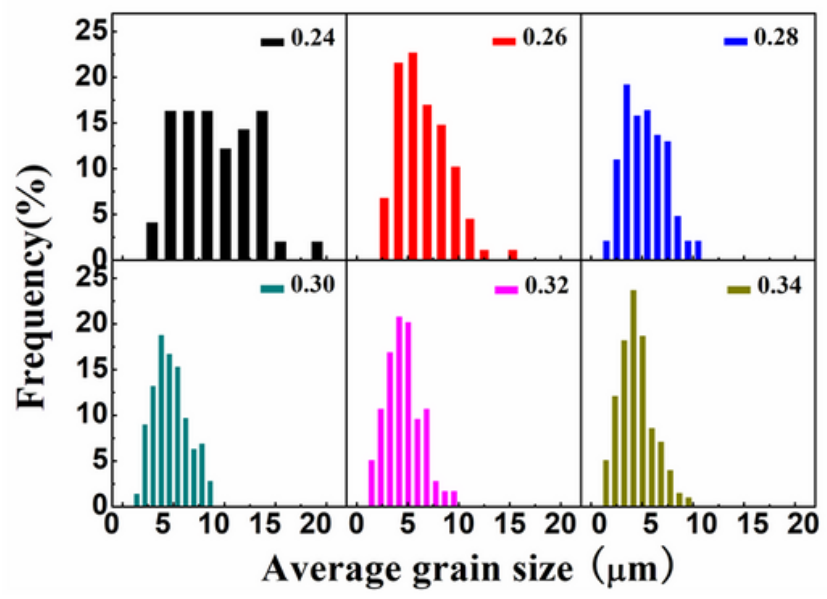

Figure 2

1. SEM images of (1-x)BF-xBT-BZT ceramics: (a) $x=0.24$, (b) $x=0.26$, (c) $x=0.28$, (d) $x=0.30$, (e) $x=$ $0.32,(f) x=0.34$. 2. Grain size distributions of $(1-x) B F-x B T-B Z T$ ceramics.

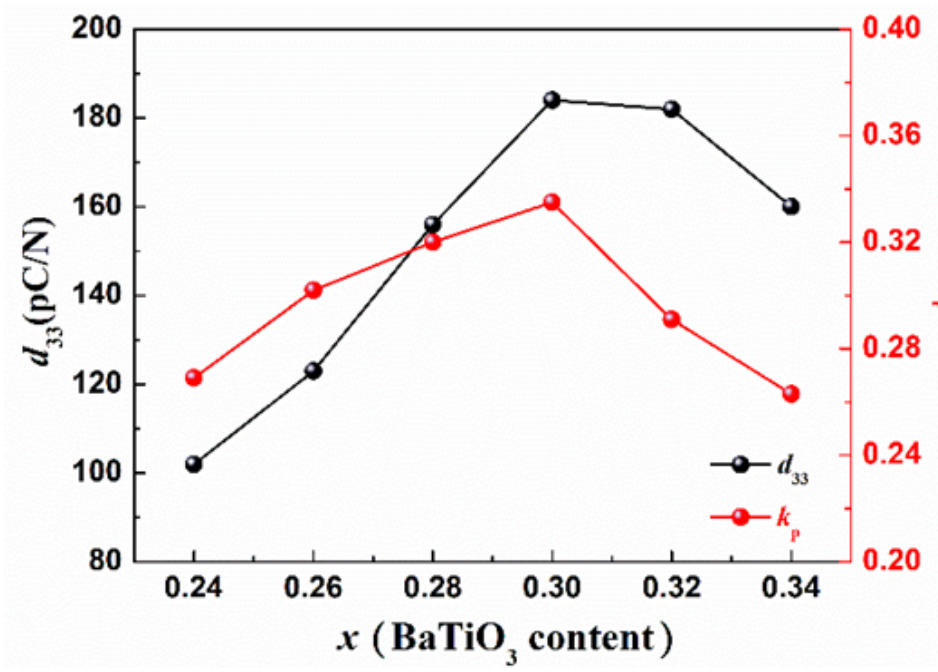

(a)

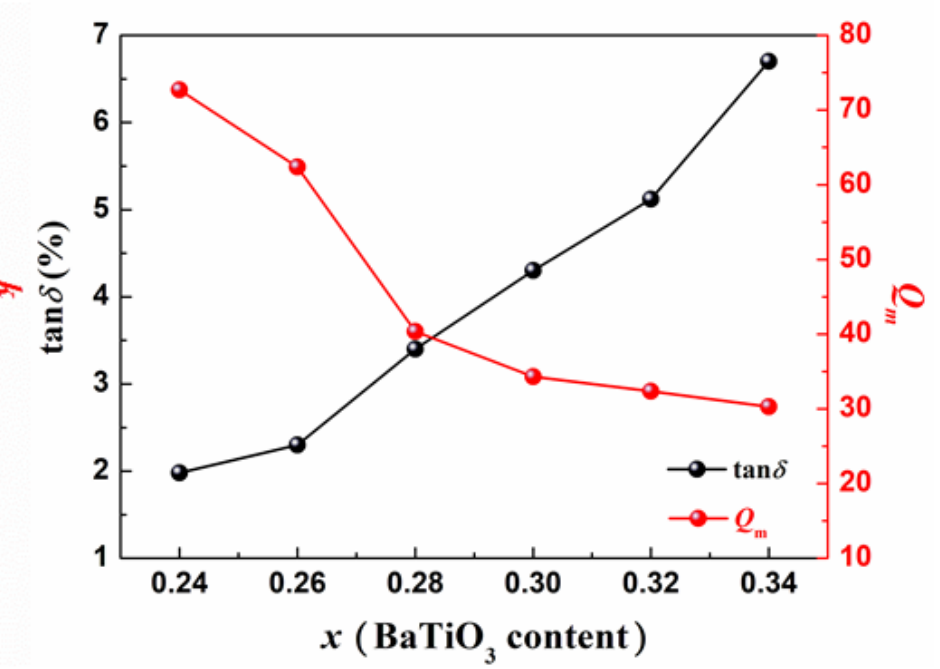

(b)

Figure 3 
(a) d33 and kp of (1-x)BF-xBT-BZT ceramics sintered at $980^{\circ} \mathrm{C}$. (b) Qm and tand of (1-x)BF-xBT-BZT ceramics sintered at $980{ }^{\circ} \mathrm{C}$.
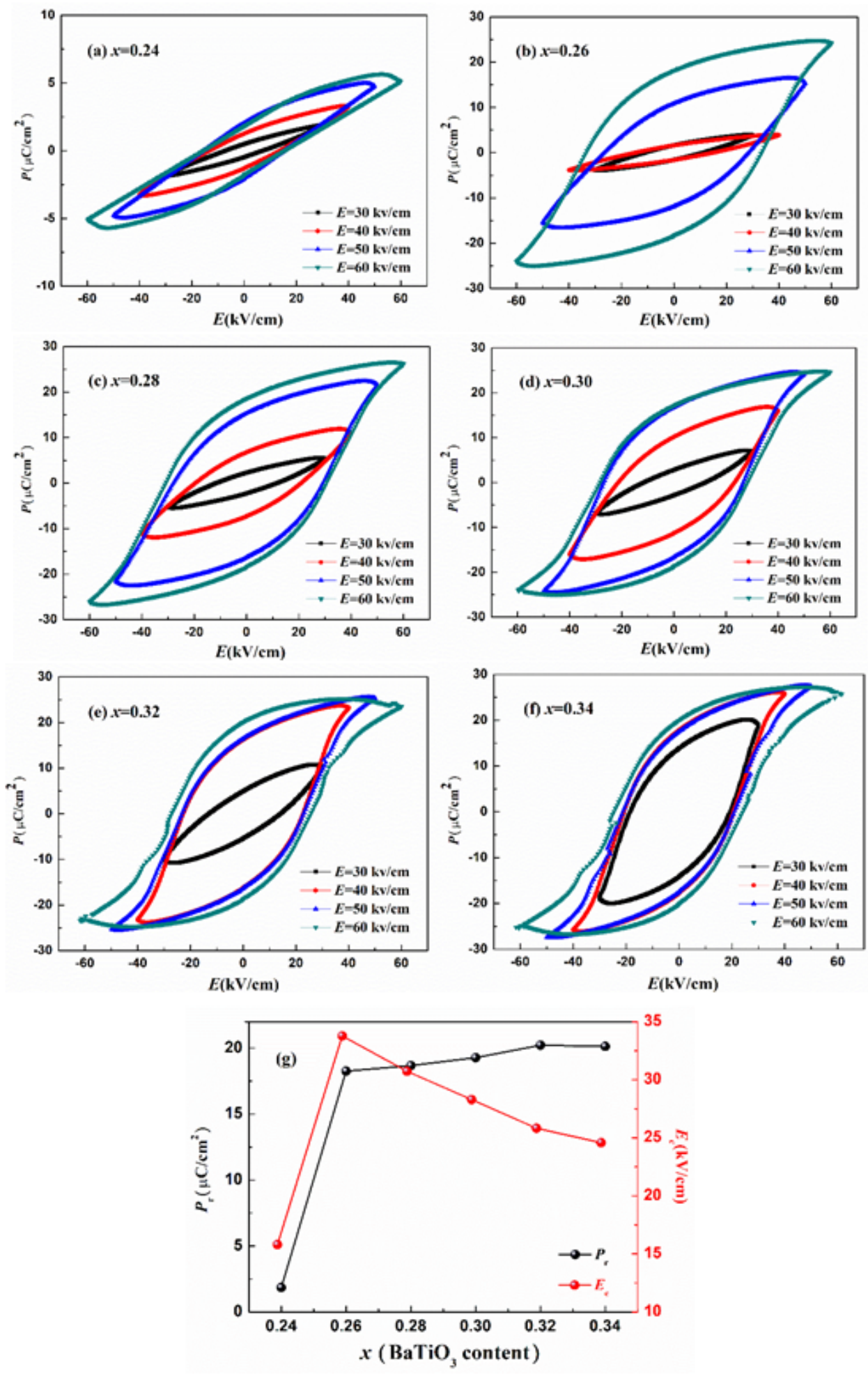

Figure 4

Room temperature P-E hysteresis loops of (1-x)BF-xBT-BZT ceramics. 

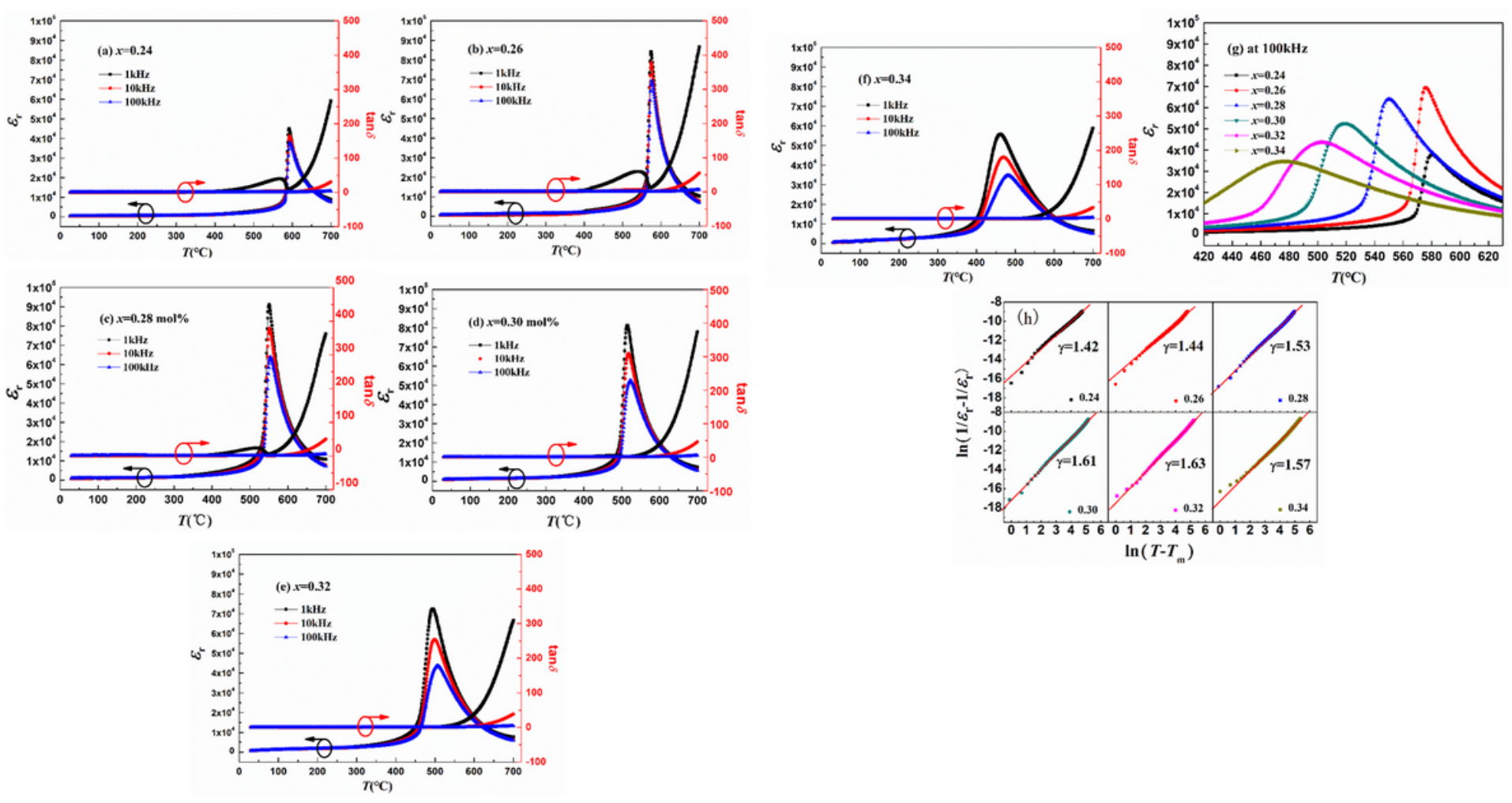

Figure 5

(a)-(f) Temperature dependence of dielectric constant Er and dielectric loss tan $\delta$ for (1-x)BF-xBT-BZT ceramics. (g) The refined temperature dependence patterns of dielectric constant at $100 \mathrm{kHz}$ with different contents of BaTi03. (h) The curve of $\ln (1 / \mathrm{Er}-1 / \mathrm{Em})$ as a function of $\ln (\mathrm{T}-\mathrm{Tm})$ for the (1-x)BF-xBT-BZT ceramic at $100 \mathrm{kHz}$. 


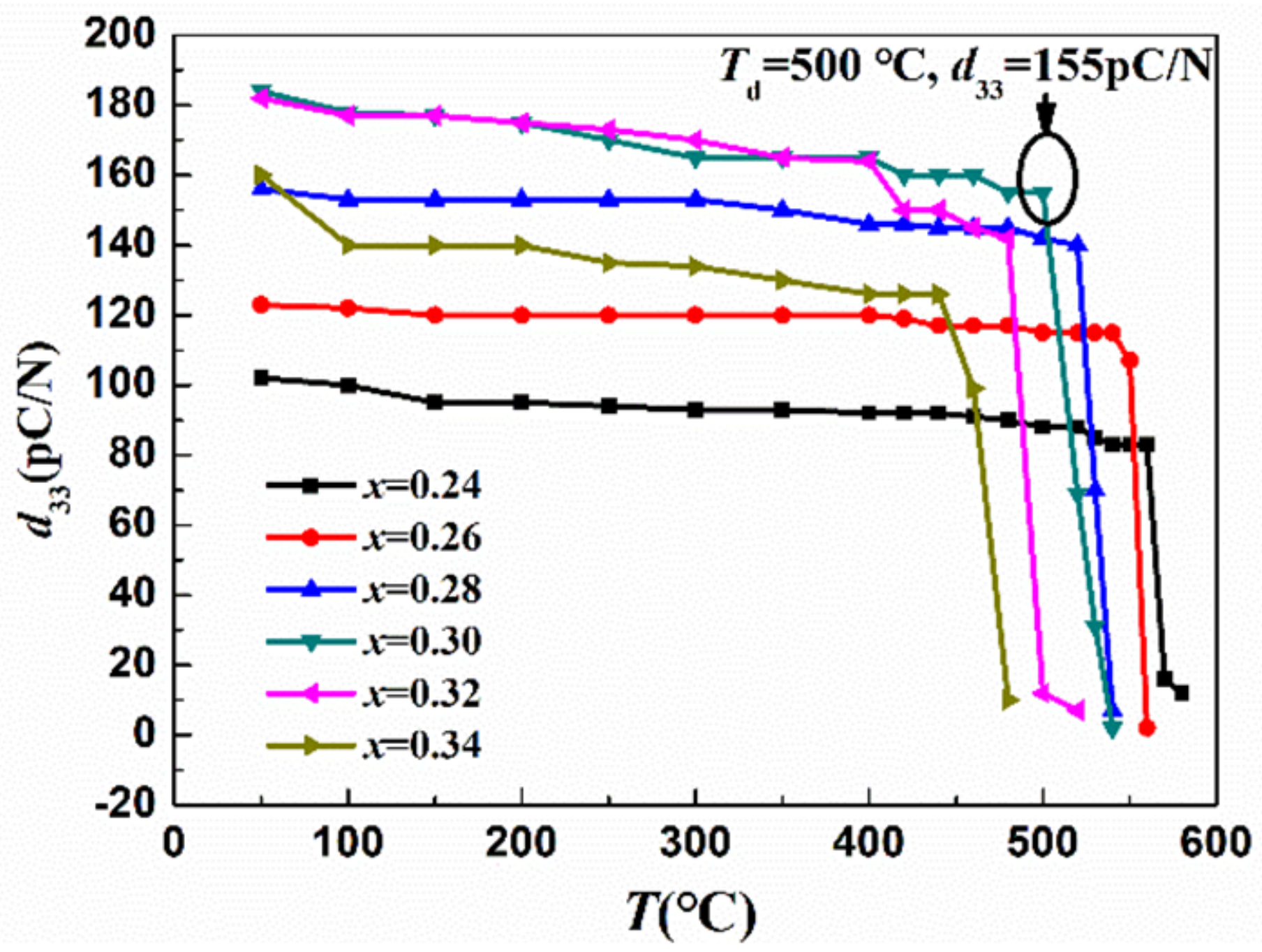

Figure 6

Temperature of piezoelectric constant d33 of poled (1-x)BF-xBT-BZT ceramics measured ex - situ. 